\title{
Linking stress and infertility-more than a chicken and egg conundrum
}

\author{
Mark P. Trolice ${ }^{1,2}$ (D) \\ Received: 3 March 2021 / Accepted: 4 March 2021 / Published online: 15 March 2021 \\ (C) The Author(s), under exclusive licence to Springer Science+Business Media, LLC, part of Springer Nature 2021
}

Keywords Stress $\cdot$ Infertility $\cdot$ IVF $\cdot$ Psychotherapy $\cdot$ Ghrelin $\cdot$ Psychological support · Cognitive behavior therapy

The earliest description of infertility dates back thousands of years [1]. Infertility has a prehistory: it was, they say, preceded by barrenness and sterility, "used to connote a divine curse of biblical proportions" and "an absolutely irreversible physical condition," respectively.

Hippocrates, back in the fifth century B.C., was one of the first to connect a woman's psychological state to her reproductive potential, theorizing that a physical sign of psychological stress in women (which scholars later dubbed "hysteria") could lead to sterility. In medieval times, a German abbess and mystic named Hildegard of Bingen proposed women suffering from melancholy - a condition that we today might call depression-were infertile as a result.

To determine the impact of stress, consider what is more distressing in the mind of a patient - a diagnosis of cancer or infertility? Domar et al. demonstrated an infertile woman's anxiety and depression scores are equivalent to one diagnosed with cancer [2]. Women who struggle to conceive are twice as likely to suffer from emotional distress than fertile women [3].

A definitive conclusion of the relationship between stress and infertility has been a matter of ongoing controversy. The literature is conflicting and confusing due to a lack of controlled prospective longitudinal studies [4]. Ultimately, the issue begs the question which occurred first - the infertility or the stress, i.e., the chicken or the egg. While evidence is clear that infertility causes stress, the reverse is an arduous and complicated hypothesis to prove with, potentially, resultant emotional consequences to the infertility patient.

Mark P. Trolice

DrTrolice@TheIVFcenter.com

1 Department of Obstetrics and Gynecology, University of Central Florida College of Medicine, Orlando, FL, USA

2 Fertility CARE: The IVF Center, Winter Park, FL, USA
The infertility patient takes offense and is psychologically damaged by the age-old advice of "just relax" because it indirectly places blame and additional stress on the already desperate and devastated woman while implying the patient has the ability to willfully rid the disease of infertility. Furthermore, by continuing to stress, the patient assumes responsibility for her heartache and her partner's, if applicable.

Most women do not begin their journey toward conception with a heightened level of stress. Unsurprisingly, stress is directly proportional to the duration of conception attempts, particularly once the women/couple are engaged in fertility treatment. An additive and unnecessary factor is the financial burden of therapy due to a lack of consistent insurance coverage. The woman/ couple increase their stress due to the guilt of submitting to the increased expense. If we consider the prevailing influencers of stress - the economy, political uncertainty, racial discrimination, personal relationships/health, job satisfaction, the country's present and future status, and COVID-19 - we can add the lack of certainty over insurance coverage for infertility treatment. Nevertheless, discontinuation of treatment is usually due to stress rather than from financial constraints or prognosis.

It has been shown that acute and chronic stress affects not only biological end-points, such as the number of oocytes retrieved and fertilized, but also influences pregnancy, live birth delivery, birthweight, and multiple gestations; in contrast, procedural stress (defined as the entire process of experiencing, perceiving, and responding to a stressor) only influences biological end-points [5]. Women are not exclusively impacted by infertility. Stress can impact libido, ovulation function, and semen which can become compromised the longer the infertility endures and during IVF [6]. Neurobiology may provide a link. Ghrelin is a gut-derived hormone and a key regulator of the endocrine response to stress and of reproduction and is believed to play a substantial role linking stress with infertility [3].

Which leads us to this month's JARG contribution from Negris et al. who present their findings of a self-administered 
32 questions survey emailed to 5000 female infertility patients to determine their belief system regarding the role of stress on fertility [7]. Of the 1460 who completed the survey, remarkably, an astounding $98 \%$ considered emotional stress caused or increased infertility. While $31 \%$ considered emotional stress as a cause of miscarriage, racial differences prevailed. Only less than a quarter of respondents believed stress played no role in infertility.

The more likely the physician was to understand a woman's cultural background, the less likely respondents implicated stress as a cause of infertility. Interpreting their physician as having a lack of understanding, patients were 2.5 times more likely to believe stress causes infertility. Lower income and less education also increased the belief of stress as a culprit. Furthermore, Black and Latino women were four and two times as likely, respectively, to link stress with infertility.

Women who used complementary and alternative medicine, black women and those who used search engines favored the link of stress and infertility. Alternatively, women who were non-religious, had a professional degree, and more infertility insurance coverage were less inclined to accept the contribution of stress. Those women who were less likely to implicate stress as a cause miscarriage were parous, had a professional degree, and more infertility insurance.

Negris et al. chose to study an area in reproductive medicine that is a profound question for the ages yet remains ambiguous. While an admirable endeavor, the study had several limitations. First, respondents only had a minimum of one visit. It is arguable that including only long-term established patients would have increased the belief of stress on infertility. Second, women up to age 58 were included. Given time lapse and the distance from infertility, respondents may minimize the impact of stress thereby falsely lowering the actual percentage of patients who believe stress causes infertility. Nevertheless, only $7 \%$ were above age 42 , limiting the impact of age. Third, most women were white, limiting the application of the study. Lastly, lower socioeconomic categorized women were under-represented possibly related to their inability to afford treatment.

Not all studies support the contribution of impaired fertility outcomes and stress. Two meta-analyses reviewed stress on outcomes of ART cycles and found no relationship [8,9].

Negris et al. will not be the last word on the impact of stress on infertility, nor is it the only survey on this topic. A recent study revealed, in both men and women, low spousal support, financial constraints, and social coercion in early years of marriage predicts infertility distress [10]. Among men, stigma, concealment, and discrimination among men were shown to be pronounced. In women with overconcerned family members who had unrealistic expectations from treatments, distress was three times greater. Subfertile individuals were socially perceived to be deprived, blemished, incomplete, and sexually incompetent.

Psychotherapy accompanying IVF has been shown to be effective [11]. In Domar's classic study on the impact of psychological support and cognitive behavior therapy and fertility, the two intervention groups had higher pregnancy rates than the control [12]. A study on depression and IVF outcome suggested that because mind/body programs are effective in reducing negative emotions that may impair IVF success, patients should be offered such a program in conjunction with IVF [13]. Recently, stress reduction has been reported to improve fertility [14].

Taken together, baseline (chronic) stress and acute (due to infertility) should be addressed prior to treatment, as proposed in Fig. 1 [15]. Short-term goals for male and female fertility patients include reduction of feelings of helplessness, through coping with infertility; changes in sexual behavior; modification of negative cognitions as to infertility; overcoming deficiencies in knowledge about fertility; and improving marital communication skills [16].

Ultimately, it remains to be determined whether negative pregnancy outcomes are impaired more by the worry of stress vs. experiencing actual stress. Nevertheless, to maximize quality of life, patients should be encouraged to understand the definition of stress - trying to control an event in which one is incapable. The debate of the true impact of stress on reproduction will continue. Until a final answer is obtained, women may continue to suffer despair and self-blame from a belief system deeply rooted for centuries.

DIAGNOSIS OF INFERTILITY

4

ESTABLISH MALE AND FEMALE CHRONIC AND ACUTE STRESS LEVELS WITH VALIDATED QUESTIONNAIRES

$\downarrow$

IF OVER THRESHOLDS:

INTENSIVE STRESS REDUCTION TECHNIQUES FOR 3 MONTHS

$\Downarrow$

ESTABLISH STRESS LEVELS AND REFERRAL TO FERTILITY CLINIC

$\downarrow$

ESTABLISH MALE AND FEMALE CHRONIC AND ACUTE STRESS LEVELS WITH PSYCHOLOGICAL AND BIOLOGICAL ASSAYS

$\Downarrow$

IF OVER THRESHOLDS:

INTENSIVE STRESS REDUCTION THROUGH PSYCHOLOGICAL AND ADJUVANT/DIETARY TREATMENTS FOR 3 MONTHS

$\Downarrow$

WHEN AND IF REDUCTION IS OBTAINED: INITIATION FERTILITY TREATMENT WITH CONCURRENT MALE AND FEMALE STRESS MANAGEMENT

Fig. 1 Addressing acute and chronic stress prior to treatment 


\section{References}

1. Flemming R. The invention of infertility in the classical Greek world: medicine, divinity, and gender. Bull Hist Med. 2013;87(4): 565-90. https://doi.org/10.1353/bhm.2013.0064.

2. Domar AD, Zuttermeister PC, Friedman R. The psychological impact of infertility: a comparison with patients with other medical conditions. J Psychosom Obstet Gynaecol. 1993;14(Suppl):45-52.

3. Sominsky L, Hodgson DM, McLaughlin EA, Smith R, Wall HW, Spencer SJ. Linking stress and infertility: a novel role for Ghrelin. Endocr Rev. 2017;38:432-67.

4. Greil AL, Slauson-Blevins K, McQuillan J. The experience of infertility: a review of recent literature. Sociol Health Illn. 2010;32: $140-62$.

5. Klonoff-Cohen H, Chu E, Natarajan L, Sieber W. A prospective study of stress among women undergoing in vitro fertilization or gamete intrafallopian transfer. Fertil Steril. 2001;76:675-87.

6. Clarke RN, Klock S, Geoghegan A, Travassos DE. Relationship between psychological stress and semen quality among in-vitro fertilization patients. Hum Reprod. 1999;14:753-8.

7. Negris O, Lawson A, Brown D, Warren C, Galic I, Bozen A, et al. Emotional stress and reproduction: what do fertility patients believe? JARG 2021;

8. Matthiesen SM, Frederiksen Y, Ingerslev HJ, Zachariae R. Stress, distress and outcome of assisted reproductive technology (ART): a meta-analysis. Hum Reprod. 2011;26:2763-76.
9. Boivin J, Griffiths E, Venetis CA. Emotional distress in infertile women and failure of assisted reproductive technologies: metaanalysis of prospective psychosocial studies. BMJ. 2011;342:d223.

10. Patel A, Sharma PSVN, Kumar P, Binu VS. Sociocultural determinants of infertility stress in patients undergoing fertility treatments. $J$ Hum Reprod Sci. 2018;11:172-9. https://doi.org/10.4103/jhrs. JHRS 13417.

11. de Liz TM, Strauss B. Differential efficacy of group and individual/ couple psychotherapy with infertile patients. Hum Reprod. 2005;20:1324-32.

12. Domar A, Clapp D, Slawsby E, Dusek J, Kessel B, Freizinger M. Impact of group psychological interventions on pregnancy rates in infertile women. Fertil Steril. 2000;73:805-12. https://doi.org/10. 1016/S0015-0282(99)00493-8.

13. Demyttenaere K, Bonte L, Gheldof M, Veraeke M, Meuleman C, Vanderschuerem D, et al. Coping style and depression level influence outcome in vitro fertilization. Fertil Steril. 1998;69:1026-33.

14. Rooney KL, Domar AD. The relationship between stress and infertility. Dialogues Clin Neurosci. 2018;20(1):41-7. https://doi.org/ 10.31887/DCNS.2018.20.1/klrooney.

15. Campagne D. Should fertilization treatment start with reducing stress? Hum Reprod. 2006;21:1651-8.

16. Pook M, Krause W, Röhrle B. Coping with infertility: distress and changes in sperm quality. Hum Reprod. 1999;14:1487-92.

Publisher's note Springer Nature remains neutral with regard to jurisdictional claims in published maps and institutional affiliations. 